\title{
El ministerio del obispo en el programa reformista de san Juan de Ávila
}

\author{
José RAMÓn Godino ALARCÓN*
}

Fecha de recepción: junio 2021

Fecha de aprobación: octubre 2021

\section{Sumario:}

El obispo fue uno de los agentes principales de la reforma de la Iglesia en el siglo XVI. Juan de Ávila, desde su postura como consejero, actor de reforma y estudioso, alentó al avance de este proceso que transformó la sociedad de su tiempo. A través de sus textos, comprobaremos su propio camino de maduración y sus aportaciones a la reforma del episcopado español.

Palabras clave:

Obispo; Juan de Ávila; Reforma

The Ministry of the Bishop in the Reformist Programme of Saint John of Ávila

\begin{abstract}
:
The bishop was one of the main agents of Church reform in the 16th century. John of Avila, from his position as advisor, reform actor and scholar, encouraged the advancement of this process which transformed the society of his time. Through his texts, we will see his own path of maturity and his contributions to the reform of the Spanish episcopate.
\end{abstract}

\section{Keywords:}

Bishop; John of Avila; Ecclesiastical eclesiástica. Reformation.

\section{Introducción}

Hace unos años, durante los estudios de doctorado, pude acercarme y profundizar en la obra reformista de san Juan de Ávila (1500?-1569). Fruto de esta investigación surgió un acercamiento, nuevo para aquel entonces, a las fuentes del recientemente creado doctor de la Iglesia ${ }^{1}$. Hoy por hoy, nuevos

" Profesor del Departamento de Historia de la Universidad Eclesiástica San Dámaso (Madrid), https://orcid.org/0000-0002-1887-123X, jose_ramongodino_alarcon@hotmail.com.

${ }^{1}$ José Ramón Godino Alarcón, Los memoriales de reforma de san Juan de Ávila: fuentes de inspiración y análisis histórico-teológico (Madrid: Universidad San Dámaso, 2018). 


\section{José RAMÓn Godino Alarcón}

trabajos han continuado el análisis de las fuentes avilistas ${ }^{2}$, dando paso a lo que ojalá pueda ser denominado, en el futuro, como un nuevo "impulso" en el conocimiento del apóstol de Andalucía.

El estudio de las fuentes nos abre a una nueva comprensión de temas que, en un autor como Ávila, parecen haber sido tratados abundantemente. Al acercarnos al ministerio del obispo en el programa reformista avilista, veremos que muchos de sus postulados, leídos con los criterios de la época, nos pueden servir para avanzar en el conocimiento de la Iglesia en España en el siglo XVI, y de la época de la Reforma católica.

\section{Los escritos de san Juan de Ávila sobre los obispos y con los obispos}

El primer paso que debemos dar es el de señalar los textos en los que el santo doctor expresó su idea del papel de los obispos, en el necesario proceso de reforma que estaba afrontando la Iglesia. Aquí debemos introducir una primera división: textos "de reforma" y los escritos conservados y conocidos, a día de hoy, en los que se plasma la relación con algunos prelados de su entorno más cercano.

\subsection{Los textos "reformistas"3}

La última edición de las obras completas de san Juan de Ávila, en su tomo II, compendia los escritos reformistas de nuestro autor. En ellos, aunque la organización necesitaría una mejora siguiendo criterios historiográficos críti$\cos ^{4}$, se puede apreciar el desarrollo del pensamiento de Ávila en lo referente a la "reformación eclesiástica". Ordenados por orden cronológico son los siguientes:

- Reformación del estado eclesiástico. Memorial I al Concilio de Trento.

- Lo que se debe avisar a los obispos.

- Memorial II al Concilio de Trento.

- De la veneración que se debe a los concilios.

- Advertencias necesarias para los reyes.

2 Juan Miguel Corral Cano, Las fuentes en el Tratado del sacerdocio de san Juan de Ávila, a la luz del conjunto de sus escritos de teología y espiritualidad sacerdotal (Madrid: Universidad San Dámaso, 2019).

${ }^{3}$ San Juan de Ávila, Obras Completas, vol. II (Biblioteca de Autores Cristianos: Madrid, 2001), 461-747. En adelante, citaremos las obras completas de San Juan de Ávila como OC, seguidas del volumen de las mismas.

${ }^{4}$ Godino Alarcón, Los memoriales..., 156-157. 
- Advertencias al concilio de Toledo (1565-1566).

- Algunas advertencias al sínodo de Toledo.

- Causas y remedios de las herejías.

Contamos, por lo tanto, con ocho textos en los que san Juan de Ávila expresó su programa reformista. En todos ellos el tema del episcopado está presente en mayor o menor medida, pero tienen especial interés los tres primeros, puesto que están ligados a la convocatoria tridentina y al papel de liderazgo que tuvo el episcopado español en la asamblea conciliar. Es cierto que el maestro nunca viajó al concilio, pero sus recomendaciones, llevadas a Trento por el arzobispo Guerrero, tuvieron especial relevancia en asuntos como el celibato del clero o la formación sacerdotal ${ }^{5}$.

\subsection{El rastro dejado en el epistolario}

Además de este corpus reformista, en las obras avilistas contamos con un nada despreciable testimonio de relación epistolar con una serie de prelados amigos que, debemos suponer, cultivaron asiduamente la relación epistolar con el santo doctor. Actualmente, y de manera desordenada, conservamos las siguientes cartas en las que Ávila abordó la reforma eclesiástica con dos obispos $^{6}$ :

- Una serie de cartas al arzobispo Guerrero:

- Una en Montilla, 2 de abril de $1547^{7}$.

- Una breve carta en torno a $1564^{8}$.

- Una en Montilla, 22 de diciembre de $1564^{9}$.

- Una en Montilla, 19 de enero de $1565^{10}$.

- Una en Montilla, 10 de marzo de $1565^{11}$.

- Una en Montilla, 5 de septiembre de $1565^{12}$.

- Una serie de tres breves cartas de $1565^{13}$.

- Cartas a Cristóbal de Rojas, obispo de Córdoba:

\footnotetext{
${ }^{5}$ Cf. OC II. $489-490$.

${ }^{6}$ Aunque sería necesario afrontar en el futuro el problema de la clasificación del epistolario de san Juan de Ávila, no compete a este trabajo solucionar un tema que, en sí mismo, merece un trabajo cuidadoso y de gran calado. Por ello, mantendremos la clasificación y datación que aparece actualmente en la última edición de las obras completas.

${ }^{7}$ Cf. OC IV. $587-590$.

${ }^{8}$ Ibid. 778.

${ }^{9}$ Ibid. 591-592.

${ }^{10}$ Ibid. $596-598$.

${ }^{11}$ Ibid. 593-595.

${ }^{12}$ Ibid. 599-600.

${ }^{13}$ Ibid. 772-774.
} 


\section{José RAMÓn Godino Alarcón}

- Una de abril o mayo de $1565^{14}$.

- Una en Montilla, 12 de noviembre de $1565^{15}$.

Tenemos, pues, once cartas de dispar longitud e importancia, casi todas ellas fechadas en la última etapa del santo doctor, en torno a 1565, el año de los sínodos provinciales de aplicación del concilio de Trento en España. Seguramente, Ávila escribió muchas cartas más a otros prelados, pero las que han llegado a nosotros, sin descartar que pudieran haber exigido muchas más, son las que hemos presentado ${ }^{16}$.

Si queremos, en vista a facilitar nuestro estudio sobre la concepción del obispo en el maestro, presentar una línea temporal con todos los escritos citados, la labor es bastante sencilla. El primer texto sería la carta al arzobispo Guerrero de 1547, seguida de los memoriales al concilio de Trento y el pequeño escrito Lo que se debe avisar a los obispos. A continuación, seguirían los escritos referentes a los sínodos provinciales (correspondencia y textos en sí) $\mathrm{y}$, por último, el tratado Causas y remedio de las herejías. Con ello, tenemos un periodo que abarca unos veinte años (1547-1567), que coincide prácticamente con la madurez y vejez de san Juan de Ávila.

¿Esto quiere decir que, en su juventud e inicio de ministerio, Ávila no abordó la reforma eclesiástica, o no cultivó la relación con distintos obispos? Sabemos que eso no es cierto, y de ello dan fe, por nombrar los ejemplos más conocidos, su trato con el arzobispo Manrique en Sevilla en una época tan temprana como $1526^{17}$, o su confianza con el arzobispo Ávalos, que lo recibió

\footnotetext{
${ }^{14}$ Ibid. 601-604.

${ }^{15}$ Ibid. 685-686.

${ }^{16}$ Respecto a la esperanza de que, en un futuro próximo, aparezcan inéditos de importancia de san Juan de Ávila, debemos constatar que, aunque no dejan de aparecer constantemente escritos desconocidos, la inmensa mayoría tienen un escaso valor a la hora de continuar con la labor historiográfica, por lo que me parece razonable pensar que, después de décadas de búsqueda, es improbable que aparezcan textos de gran importancia o extensión del santo doctor. Ojalá en un futuro pueda admitir esta suposición como un error ante el descubrimiento de alguna pieza de gran interés.

${ }^{17}$ Fray Luis de Granada, Vida del Venerable Padre Maestro Juan de Ávila. Parte III, capítulo IV: "Llamado, pues, el padre, alegando lo que arriba está dicho, y excusándose todo lo posible, después de muchas razones, finalmente, el Espíritu Santo, que por los Pontífices declara muchas veces su voluntad, de tal manera se aficionó a este padre, que le mandó por precepto de santa obediencia, que se quedase en su arzobispado, y así se quedó. Y luego le mandó que predicase; y aunque él se excusó, como nuevo en aquel oficio, todavía lo hubo de hacer. Y el sermón fue en la iglesia de San Salvador, día de la Madalena, asistiendo allí el Arzobispo con otra gente principal; y fue éste el primer sermón que predicó.

Contó después el padre a uno de sus discípulos que se había hallado muy apretado antes que subiese al púlpito, y muy ocupado con vergüenza. Y como así se viese, levantó los ojos a un Crucifijo que allí estaba, diciendo estas palabras: «Señor mío, por aquella vergüenza que Vos padecisteis cuando os desnudaron para poneros en la Cruz os suplico que me quitéis esta demasiada vergüenza y me deis vuestra palabra para que en este sermón gane alguna ánima para gloria vuestra». Y así le fue concedido. Y dijo después el padre a uno de sus discípulos, que había sido éste uno de los grandes sermones
} 
en Granada tras el proceso inquisitorial y una primera etapa en Córdoba ${ }^{18}$. Únicamente, no tenemos ningún escrito de san Juan de Ávila que confirme lo que testimoniaron los biógrafos y amigos de la época, por lo que no podemos hacer más que suposiciones. Además, lo verdaderamente interesante no es en este punto atestiguar la cercanía de Ávila a un gran número de prelados, algo que damos por supuesto en él, y en lo que podemos además afirmar que, conociendo su personalidad, no puso especial dedicación ni le dio gran importancia. Es a partir de la convocatoria conciliar y de la necesidad de un proyecto reformista válido para toda la Iglesia, cuando surge un auténtico programa en el que, necesariamente, san Juan de Ávila abordó la figura del obispo y los aspectos en que debía ser reformada.

Comprendiendo las fuentes de su comprensión y el contexto histórico, podremos hacernos una idea de la línea reformista y de los temas principales en los que se centra el santo maestro.

\section{La reforma del episcopado, eje de la reforma eclesiástica española}

Un punto que nunca debemos olvidar es que, dentro del proceso de reforma de la Iglesia durante la Edad Moderna, el inicio y motor de esta estuvo en los reinos hispánicos, especialmente en Castilla. Y que sus grandes artífices tuvieron nombre y apellidos, y que sin ellos todo hubiera sido muy diferente: los Reyes Católicos y el cardenal Cisneros ${ }^{19}$.

que había predicado y de más provecho; y así dejó a los oyentes grandemente maravillados, viendo el espíritu y fervor con que predicó.

Comenzó, pues, a predicar con este mismo fervor como siempre solía, y así movía grandemente los corazones de los que le oían. Aquí se llegó a él el padre Contreras, de que arriba hecimos mención, y algunos clérigos virtuosos que trataron familiarmente con él y se aprovecharon de su dotrina. Predicaba también en los hospitales y seguíale mucha gente. Comenzó también a dar orden en las escuelas de los niños y a predicar la Dotrina cristiana por las plazas; y en este oficio perseveró en Sevilla por algún tiempo.

${ }^{18}$ José Ramon Godino Alarcón, "La escuela sacerdotal "avilista" (en prensa) (Córdoba, 2021). En este trabajo abordo la importancia de la relación con Ávalos en el proyecto avilista, en especial en lo referente a la formación sacerdotal y a la renovación de la vida religiosa. Esta etapa supuso la antesala del proyecto de universidad en Baeza, cumbre del método educativo de san Juan de Ávila".

${ }^{19}$ Una de las claves del impulso reformista español fue, precisamente, la mejora de las condiciones del clero diocesano, tanto en lo formativo como en el desarrollo del ministerio. La reforma eclesiástica, que se inició ya en época de Juan II (1405-1454), pero que tuvo su auténtico esplendor durante el reinado de Isabel la Católica (1474-1504), partió del segmento más importante del clero: los obispos. Reformar el episcopado no repercutía únicamente en las cabezas de la Iglesia, sino que tuvo unos efectos muy claros en el sacerdocio. El principal, sin lugar a duda, fue el abandono del régimen feudal en favor de la intervención real para la provisión de las diócesis, imponiendo las famosas "cuatro condiciones" que se buscaron desde ese momento para los prelados y más importantes dignidades eclesiásticas: de estos reinos, letrados, honestos y de "clase media". Cf. Tarsicio de Azcona, 


\section{José RAMÓn Godino Alarcón}

San Juan de Ávila no ideó ex novo un proceso de reforma de la Iglesia, ni tampoco fue un revolucionario en sus propuestas. Fue, más bien, un continuador de lo que se había iniciado a finales del siglo XV y que alcanzó su plenitud en las primeras décadas del siglo XVI: la idea de una reforma del estado eclesiástico, en la que cada parte asumiera sus responsabilidades y comunicara la virtud en una suerte de "vasos comunicantes". De ahí que los obispos, que estaban en la cúspide de la estructura eclesiástica, debían tener un singular cuidado de transmitir al clero, y a través de él a los fieles, un estilo de vida virtuoso y de piedad.

Es en este contexto en el que se movió el santo doctor. No podemos decir que, a principios del siglo XVI, todos los obispos castellanos fueran un dechado de virtud, pero sí que se tenía una imagen determinada del "perfil" que debía demostrar el prelado, y que había demostrado ser exitoso. Se puede decir que la situación estaba en vías de solución, y que eran muchas más las luces que las sombras a la hora de evaluar la situación eclesiástica ${ }^{20}$.

San Juan de Ávila fue, en este sentido, un heredero de un trabajo de décadas, en el que siguió profundizando en un terreno ya cultivado y floreciente. ¿Eso supone que él y su época no supusieron ninguna novedad? Merece la pena detenerse en este aspecto.

Mientras que el gran impulso reformista puede identificarse, con bastante acuerdo, con el reinado de los Reyes Católicos, el reinado de Carlos V supuso una continuidad que, en torno a 1540, presentaba síntomas de cansancio y de no poder afrontar los cambios revolucionarios que venía arrastrando la Iglesia universal desde 1517. Este era el gran problema. Mientras que la situación hispana aparecía bastante saneada, el panorama en el resto de la Iglesia era bastante más desolador y necesitaba de una actuación certera. El emperador intentó abanderar un proyecto reformista que seguía conservando resabios de la época medieval, especialmente en lo referente a la superioridad del emperador sobre los estados nacionales. Esta tesis se demostró superada por los acontecimientos y, con ella, la idea de que el emperador, junto con el papa, podían pilotar solos la restauración de la unidad de la Iglesia en los inicios de la Reforma protestante. El camino de la renovación debía ir acompañado de una comprensión moderna del nuevo ordenamiento europeo, que había renegado de la idea de cristiandad.

Felipe II supuso un cambio de paradigma respecto a los ideales de su padre. Abandonada la idea imperial y asumida la división irremediable de la

La elección y reforma del episcopado español en tiempo de los Reyes Católicos (Madrid: Instituto P. Enrique Flórez, 1960).

${ }^{20}$ Javier Fernández Conde, «Decadencia de la Iglesia española bajomedieval y proyectos de reforma», en Historia de la Iglesia en España. La Iglesia en la España de los siglos XV y XVI, vol. II-2, editado por Ricardo García Villoslada (Madrid: Biblioteca de Autores Cristianos, 1980), 417-462. 
Iglesia, el rey prudente entendió su liderazgo como la propiciación de una reforma interna que restaurara la vida eclesiástica, sin pedir imposibles ${ }^{21}$. Es en esta época en la que se introduce, ad intra, una "reforma católica", tachada posteriormente ad extra como "contrarreforma", sin que este apelativo resultara excesivamente molesto para la parte católica más apologética ${ }^{22}$.

La Iglesia católica, a la altura de 1550, no se consideraba en un proceso "contrarrevolucionario", sino haciendo un auténtico "encaje de bolillos" que no rompiera aún más la unidad y que diera pasos decididos para la solución de un problema secular que siempre encallaba debido a distintos conflictos de autoridad: el papa con el emperador, la curia romana con los obispos, los obispos con los religiosos, el clero secular desprovisto de medios y formación... Por unas cosas o por otras todos los intentos de renovación fenecían en documentos llenos de amenazas y penas que luego no se podían llevar a la práctica.

En época de Felipe II se plantea, además, una disyuntiva que llevaba tiempo presente y que planteó problemas tanto teóricos como prácticos: la necesidad o no del uso de la fuerza para conseguir la reforma eclesiástica, y quién debía ejercerla. En España este problema tenía fácil solución, consecuencia del patronato regio, pero esto no dejaba de poner en entredicho la capacidad del romano pontífice para conducir los distintos procesos abiertos, especialmente la necesidad de culminar lo iniciado en Trento en 1543. El rey tenía claro que se debía usar la fuerza en caso de necesidad, y que el responsable debía ser cada monarca en sus reinos, pero para eso debía vencer los temores de la Santa Sede a perder el control del concilio y, especialmente, que reviviera un conciliarismo que impusiera una reforma del papado. Todo esto se puede resumir en una tensión ante la propuesta de una "españolización" de la Iglesia a mediados del siglo XVI. Y no cabe duda de que san Juan de Ávila fue partidario entusiasta de esta tendencia ${ }^{23}$.

El concepto de Iglesia que encontramos en los memoriales de reforma y en las cartas es, pues, el producto de un siglo de transformación eclesial en España, y su resultado visible es la firmeza. Es el de la solidez disciplinar y

\footnotetext{
${ }^{21}$ Con este punto de vista podríamos intentar, al menos, conciliar las posturas de los grandes historiadores de esta época, divididos entre el concepto de "contrarreforma" y "reforma católica". Cf. Giuseppe Alberigo, «Dinamiche religiose del Cinquecento italiano tra Riforma, Riforma cattolica, Controriforma», Cristianesimo nella storia 6, (1985): 543-60; Heinrich Lutz, Reforma y Contrarreforma (Madrid: Alianza Universal, 1992).

${ }^{22}$ Siendo fieles a la historia, debemos señalar que el término "contrarreforma" no fue acuñado en la época que posteriormente sería denominada de esta manera, sino que es un producto de la Ilustración a la hora de presentar los esfuerzos católicos de consolidación y apostolado en Centroeuropa. Gracias a este empuje misionero muchos territorios germánicos se mantuvieron en la órbita católica, y muchos otros volvieron con el tiempo a ella. Cf. Lutz, Reforma ..., 262-267.

${ }^{23}$ Esta idea aparece en varias obras de José Ignacio Tellechea Idígoras. Véase, por ejemplo, Felipe II y el Papado (Madrid: Fundación, 2004-2006).
} 


\section{José RAMÓn Godino ALARCón}

dogmática, que había ofrecido una gran estabilidad, en una época en la que la libertad se medía de manera distinta que en nuestros días. Es la mezcla entre el plano político y el religioso, hasta llegar a un momento en el que no se sabe muy bien de qué se está hablando, o, mejor dicho, no se puede hablar de una cosa sin la otra. Es un movimiento que había de poner en marcha a la Iglesia universal y que tenía como mejor embajador a san Ignacio de Loyola. Y, precisamente, detrás de todo esto, estaba san Juan de Ávila. De ahí el gran interés que tiene su concepción para saber cómo se había edificado una Iglesia que no tenía miedo de ser católica ni misionera ${ }^{24}$.

Por lo tanto, aunque la historiografía actual no sea muy favorable a esta visión, encontraremos esta mirada positiva sobre las instituciones y la reforma eclesial en los textos de Juan de Ávila, como una adaptación de la vida eclesial a la modernidad, aunando los planos espiritual y material. Algo en lo que el santo doctor, dotado de una visión práctica para sus proyectos, destacó ciertamente. Lo vemos claramente representado, tanto en los datos de los memoriales, como en lo expresado en la relación epistolar.

\section{La visión de san Juan de Ávila sobre el episcopado en los memoriales para el concilio de Trento}

Los memoriales de reforma nos dejan una verdad de fondo que nos puede ayudar para entender el conjunto de todo el programa reformista del santo doctor: no se trata de cambiar estructuras, como habían propugnado a su manera la curia romana y los protestantes, sino de elegir mejor a las personas que tenían que darles vida ${ }^{25}$. La Iglesia necesitaba cambios profundos tras la Re-

\footnotetext{
${ }^{24} \mathrm{Y}$ de ahí que grandes autores de la historia de la Iglesia, como García Villoslada, vieran el concepto de contrarreforma desde un punto de vista positivo: "La Contrarreforma es la verdadera reforma moral y espiritual de la Iglesia romana en el siglo XVI, como fruto maduro de mil tentativas anteriores (...). Es una reforma disciplinar y canónica (...), es el brío inquisitorial del Papa Carafa, la santidad orante y militante de Pío V (...), las órdenes religiosas nuevas y las reformadas (...). La Contrarreforma es la teología escolástica rejuvenecida por Francisco de Vitoria (...), el ascetismo riguroso de Pedro de Alcántara, el paulinismo de Juan de Ávila, los escritos de Luis de Granada, la Noche Oscura y la Llama de amor vivo del tenue fraile carmelita y el grito de guerra lanzado por santa Teresa a sus monjas contemplativas en sus últimas Moradas: 'Todos los que militáis debajo de esta bandera - ya no durmáis, ya no durmáis - pues que no hay paz en la tierra'; es el ímpetu conquistador de los misioneros y toda la inmensa literatura que va desde fray Luis de León, Torquato Tasso y Lope de Vega hasta Friedrich Spee, Angelo Silesio y el gran arte del Manierismo y del Barroco, el misticismo musical de Tomás Luis de Victoria y la polifonía de Pier Luigi da Palestrina significan la exaltación más serena de la Contrarreforma”. Ricardo García Villoslada, «La Contrarreforma. Su nombre y su concepto histórico», en Saggi storici intorno al Papato (Roma: Pontificia Universidad Gregoriana, 1959), 189.

${ }^{25}$ Miguel Navarro Sorní, «San Juan de Ávila y la reforma de la Iglesia», en San Juan de Ávila,
} 
forma protestante, pero era imposible pensar que podía "refundarse" desde la nada. Desde el realismo, el maestro Ávila desarrolló un plan mediante el cual, con paciencia y tiempo, se fuera realizando un reemplazo que diera paso de forma tranquila a una Iglesia reformada. Justo lo que, durante años, se había visto en España con la paulatina reforma del episcopado.

De este modo, los planteamientos de los memoriales de reforma no son teóricos, sino prácticos. Y, por ello, no se aborda directamente la reforma del episcopado por dos motivos: porque el concilio de Trento en ese punto parecía haber encallado ${ }^{26}$, y las disensiones entre la curia romana, el resto del episcopado y los representantes diplomáticos parecían de imposible solución. Además, el camino ya había sido marcado en España desde el siglo anterior y se habían comprobado sus beneficios. Ávila prefirió enfrentar el problema de la formación del clero y la selección de los candidatos a las órdenes, sabiendo que en esos puntos sería decisiva la figura del obispo.

Ya antes de escribir el primer memorial que conservamos, el de 1551, san Juan de Ávila había aconsejado, que tengamos constancia, al arzobispo Guerrero, sobre lo que debía tratarse para la reforma de la Iglesia. Testimonio de ello es la carta $177^{27}$, dedicada al recién nombrado arzobispo.

Sin querer hacer hincapié en las consideraciones espirituales que se hacen en la carta, desde el primer párrafo se nota que la misiva está destinada a un prelado en sintonía con la reforma y con los criterios del santo maestro. De ahí que la primera nota que se puede destacar es la consideración del episcopado como una carga, no como un honor del que había que lucrarse ${ }^{28}$. Ávila era consciente de que Guerrero necesitaba su ayuda y consejo, aunque no podía desplazarse hasta Granada para ayudarle. Por ello, de una forma sencilla, el maestro dio al prelado una serie de advertencias que, en palabras del autor, "las cuales son a vuestra señoría manifiestas, más descansaré yo con decirlas”29. En pocos folios Ávila sintetizó muchos de los consejos que luego desarrolló en los memoriales. En lo que respecta a la figura del obispo, podemos señalar los siguientes rasgos:

Doctor de la Iglesia, editado por Nicolás Álvarez de las Asturias (Madrid: Universidad San Dámaso, 2013) 49-85.

${ }^{26}$ El deber de residencia de los prelados, uno de los puntos más importantes del concilio, no llegará a debatirse y a formular cánones hasta la Sesión XXIII (15 de julio de 1563).

${ }^{27}$ OC IV, 587-590. La carta se conservó en el Colegio de Montilla, desde donde fue enviada a Roma en 1739 con motivo de la aprobación de los escritos. Para su datación se tomó que, por el contenido, tenía que estar ligada a la toma de posesión de Guerrero de la sede de Granada (20 de noviembre de 1546). La primera publicación de esta carta y el resto del "cuaderno" en que se conservaban se publicó por primera vez, según Santiváñez, en 1618.

${ }^{28}$ OC IV, 587: “Compasión muy entrañable me ha causado vuestra señoría, porque se me traslucen los muchos gemidos que esta pesada carga le ha de dar (...)".

${ }^{29}$ Ibid. 588. 


\section{José Ramón Godino Alarcón}

- Necesidad de ser hombre de oración. Ávila señaló el deber del obispo como "pontífice", intercesor entre Dios y los hombres. Un trabajo que se debía realizar de manera constante ${ }^{30}$. El santo doctor, además, señaló un aspecto que puede ser considerado la distinción entre un obispo piadoso o mundano: la celebración cotidiana de la Misa, costumbre que no estaba extendida en la época ${ }^{31}$.

- El ejercicio de la predicación. Juan de Ávila consideró uno de los aspectos más altos del ministerio sacerdotal el púlpito ${ }^{32}$. Esto, que señaló constantemente para los sacerdotes, y en lo que hará un gran hincapié en los memoriales a Trento, se debía aplicar necesariamente al obispo. Los prelados podían correr el peligro de no predicar más que en circunstancias extraordinarias, cediendo a otros predicadores más brillantes la tarea, pero con ello hacían dejación de funciones puesto que no era tan importante, en este caso, el contenido, sino la personificación del obispo como buen pastor $^{33}$. Como ejemplo para Guerrero Ávila puso al cardenal Ávalos, también gran amigo del maestro y entusiasta partidario de la reforma.

Pero la predicación no solo debía cuidarse en la catedral o en la ciudad, sino que debía vigilarse para que en toda la diócesis hubiera predicadores preparados y disponibles, algo complicado dada la escasa formación del clero secular. Trasponiendo su mismo estilo de vida sugirió nombrar predicadores que se desplazaran por todo el obispado ${ }^{34}$. El problema era, como constató el propio Ávila, que no se contaba con muchos candidatos para ese perfil. De ahí la necesidad de poner empeño en la formación de nuevos sacerdotes que pudieran cubrir estas necesidades.

- La obra de los colegios. Mientras que el texto de 1551 será una exposición pormenorizada para fundar colegios para la formación de los clérigos en toda la Iglesia, en la carta a Guerrero se refirió a la situación concreta de Granada, donde había trabajado intensamente ${ }^{35}$. Ávila reco-

\footnotetext{
${ }^{30}$ Ibid. 588: "Que vuestra señoría se convierta de todo su corazón al Señor, frecuentando el ejercicio de la oración, encomendando a la misericordia divina el buen suceso del bien de sus ovejas y pidiendo el sustento del cielo (...)".

${ }^{31}$ Ibid. 589: "Y será bien que cada día vuestra señoría diga misa, si muy legítimo impedimento no hubiere".

${ }^{32}$ Así lo reflejó en el Audi filia, su obra cumbre que atravesó su juventud y madurez en el proceso de redacción. Desde este texto podemos comprender cómo la importancia de la predicación acompañó a san Juan de Ávila desde el primer momento de su vida apostólica: "Porque sin Cristo no se inflaman los corazones ni se vuelven a nuestro Señor; y así es la impresa de predicadores portare nomen Domini Iesu, et divitias illus evangelizare" (OC I, 827).

${ }^{33}$ OC IV, 589: “(...) Pues los lobos no cejan de morder y matar, no debe el prelado dormir ni callar”.

${ }^{34} \mathrm{Ibid}$. 590: "Menester eran predicadores devotos y celosos, para discurrir por el arzobispado a ganar almas, que tan perdidas están".

${ }^{35}$ A su llegada a Granada en la década de 1530, san Juan de Ávila colaboró en el desarrollo de los
} 
mendó al nuevo arzobispo que cuidara especialmente la selección de los superiores y la admisión de los candidatos, uno de los puntos en los que más severo fue en sus escritos reformistas. En concreto, Ávila pidió que se favoreciera el colegio de santa Catalina, de reciente fundación y que necesitaba tener suficientes alumnos para poder garantizar su funcionamiento $^{36}$. En el "espíritu" de la carta subyace la preocupación, tanto del maestro como del arzobispo, por la falta de personas preparadas para poder continuar los impulsos reformistas. Era bastante razonable que el primer esfuerzo fuera conservar lo ya creado y no dejar que cayera en el olvido.

- El "tono de vida". Con este título se pueden agrupar una serie de consejos prácticos que debían caracterizar a la figura del obispo. En ellos se incluía el no tener excesivas amistades que luego se aprovecharan en beneficio propio ${ }^{37}$, no confundir la dulzura de las palabras con la pusilanimidad $^{38}$, la austeridad de vida ${ }^{39}$ y el cuidado de los pobres ${ }^{40}$.

A partir de estas coordenadas, podemos encuadrar los consejos avilistas dentro del plan general de reforma que estaba motivando la asamblea tridentina. Un primer punto, en el que todos los historiadores están de acuerdo, era el de la obligación de residencia de obispo y párrocos. No dedicó ninguna línea a este particular el maestro en sus textos dedicados al concilio, pero desde sus escritos está claro que, sin un obispo atento a su diócesis, no se podían formar adecuadamente los candidatos al presbiterado. A san Juan de Ávila le preocupaba especialmente que el ordinario debía conocer personalmente a los futuros sacerdotes, y que debía garantizar que se les examinara adecuadamente, incluso bajo su propia dirección ${ }^{41}$. Este particular se muestra aún

colegios Eclesiástico, de san Miguel y de santa Catalina, en colaboración con el arzobispo Ávalos. Esta época puede ser considerada la "preparación" para la posterior fundación de Baeza. Cf. Godino Alarcón, La escuela...

${ }^{36}$ OC IV, 589-590: "Conviene favorecer el Colegio de Santa Catalina, porque de allí se han de proveer oyentes para la teología; y pues hay en él también rector, vuestra señoría le favorezca".

${ }^{37}$ OC IV, 589: "Particulares amistades de caballeros ni de otras personas excuse vuestra señoría, porque son dañosas (...) Mejor es estar sin ellos".

${ }^{38} \mathrm{Ibid}$. 589: "Y aunque en las palabras sea blando y dulce, sea en las obras duro y rígido, cuando sea menester".

${ }^{39}$ Ibid. 589: "Cama de seda no cumple, y paños de corte tampoco". Llama la atención aquí la mención del IV Concilio de Cartago, lo que nos da una muestra del conocimiento de san Juan de Ávila de las colecciones de cánones y del derecho eclesiástico, en contra de la idea que se pudiera tener de que recelaba de estas materias.

${ }^{40} \mathrm{Ibid}$. 590: "Una persona discreta y fiel es menester para que examine necesidades de pobres que están en sus casas, para que les provea lo necesario".

${ }^{41}$ Así lo expresa con claridad en el memorial de 1551: "Pues, conforme a esta autoridad y ejemplo, los que hubieren de ser elegidos para estos colegios sean de los mejores que hubiere en todo el pueblo, haciendo inquisición de ello muy de raíz el obispo y los que el concilio les señalare por acom- 


\section{José RAMÓn Godino Alarcón}

más necesario a la hora de otorgar las licencias de confesión ${ }^{42}$. Es más, Ávila descargó el peso de la decisión final en el obispo, sugiriendo que quienes no tuvieran celo a la hora de vigilar a quién ordenaban fueran condenados con la excomunión ${ }^{43}$. Para ello, evidentemente, el obispo debía estar suficientemente preparado, y por ello Ávila sugirió en el memorial de 1551 que no pudiese ser nadie nombrado obispo sin haberse graduado antes en teología ${ }^{44}$.

En el plan educativo de Ávila, además, hay un dato que podría pasar desapercibido y que, sin embargo, es de gran importancia: para el doctor de la Iglesia los candidatos debían ser elegidos, no postularse personalmente. Este punto resulta verdaderamente sorprendente, casi un arqueologismo, pues lleva al extremo la concepción de que la vocación sacerdotal es señalada por la Iglesia, encargada de confirmar el deseo del candidato. San Juan de Ávila fue más allá, pues al pensar que el sacerdocio era la vocación más alta a la que podía ser llamado un hombre, era la Iglesia la que debía llamar al candidato a iniciar su formación, y no al revés (como sucedía y sucede en la práctica). El maestro distinguió entre los "llamados", y los que "llamaban", considerando a estos últimos un inconveniente y considerando que en su vigilancia debía estar muy centrado el obispo, separando ambas clases de candidatos y poniendo mucho cuidado en la elección de los superiores que velaran por la formación de quienes deseaban ser eclesiásticos. Merece la pena leer al santo doctor en una página que parece que pasa muchas veces desapercibida:

Otro inconveniente hay, y no menor, contra la dicha orden dada, y no ha menester menor remedio; y es que, como el deseo de ser eclesiástico esté en algunas personas muy arraigado por diversos fines, no han de querer esperar a ser llamados, sino han de venir a llamar y quebrar las puertas, pidiendo que quieren ser clérigos y que los metan en los colegios; que ellos quieren pasar por

pañados. Y de esta manera vendrán llamados y no injeridos, y entrarán por la puerta de obediencia y llamamiento de Dios (...)" (OC II, 495).

${ }^{42} \mathrm{Ibid}$. 504: "Notorio es lo mucho que va en ser los confesores lo que deben ser, porque todo viene a sus manos. Si éstos fueren cuales deben, todo sería remediado. Y por esto parece ser cosa conveniente de que ninguno pudiese confesar, clérigo ni religioso, sin ser examinado personalmente por el obispo y sin tener licencia de él".

${ }^{43}$ Ibid. 496-497: "Porque ¿qué mayor mal puede ser para todos los oficios que admitir a ellos por sola voluntad de los que los quisieren tomar? Y en éste, por ser más alto y de mayor perjuicio a la Iglesia, será mayor mal. Y, por tanto, se deben buscar medios y poner todo recaudo para que no sean admitidos al estado clerical sino los hábiles; $y$, si otros fueren, sean expelidos sin respeto alguno. Y para esto deben poner graves excomuniones a los prelados y acompañados, conforme a las que se ponen a los inquisidores cerca del uso del oficio, para que por ninguna vía admitan a la educación eclesiástica al que no pareciere ser digno(...)".

${ }^{44}$ Ibid. 510: "Cuánto vaya en que el prelado sea el que debe, a todos es notorio, y por eso se ha de mirar que sea criado en toda disciplina eclesiástica y virtud, y mucho más que los otros clérigos (...) Y para bien predicarlo es menester bien aprenderlo, sería cosa conveniente que ninguno pudiese ser elegido un obispo si no fuere graduado en universidad a lo menos en bachiller en teología". 
el rigor de ellos. A éstos se les debe decir cuán mal hacen en injerirse y cuán peligroso estado es éste por la alteza de él y flaqueza nuestra; y que piensen en ello más despacio, como en cosa que mucho les va; y darles razones de cómo no es tan seguro como ellos, con su poca experiencia, piensan.

Y es cierto que, después de todo, ha de haber muchos que ni el rigor de la disciplina ni consejo de nadie les baste para quitarse de su propósito. Y parece que para éstos será bien que haya otra casa a modo de colegio, en la cual se ponga una persona buena y docta por mano del obispo, y allí vivan de la misma manera que en los otros colegios, salvo que vayan a oír las lecciones a los dichos colegios, por no hacer costa doblada para tener maestros; y allí entren y vivan los que quisieren ser clérigos, sin esperar ser llamados, y si fueren los que deben, el obispo y electores los pasarán de allí a otros colegios $(. . .)^{45}$.

Vemos, pues, cómo el obispo debía tener un conocimiento directo y personal de los candidatos al sacerdocio. Esto era imposible si no residía en la diócesis y si no se tomaba en serio la necesidad de una formación sólida, con cargos de confianza que le informaran puntualmente. Sorprende, además, que sugiriera la creación de un colegio "disuasorio", pero que no costara demasiado mantener. Sin hacer referencia al deber de residencia, san Juan de Ávila dio motivos razonables y prácticos que justificaban la necesidad de ella. Si el obispo no estaba presente en su obispado, no podía examinar a los clérigos ni estar al tanto de la marcha de los colegios.

Ahora bien, el deber de residencia había sido interpretado desde la corona como una ocasión para convertir al episcopado en una representación más de la autoridad de la monarquía. Muchos, empezando por grandes obispos como Talavera, Mendoza o Cisneros, habían dedicado más tiempo a labores de estado que al gobierno de sus diócesis. Pero esto debían ser excepciones puntuales, no la norma. Por ello san Juan de Ávila advirtió severamente que el obispo no debía desarrollar autoridad secular, sino contentarse con la autoridad en el fuero eclesiástico, como una muestra de la estima de la dignidad episcopal ${ }^{46}$. Por decirlo de alguna manera, al maestro le preocupaba que la monarquía española convirtiera la labor del obispo en algo secundario, dando preponderancia a la jurisdicción civil ${ }^{47}$.

\footnotetext{
${ }^{45}$ Ibid. 503-504.

${ }^{46} \mathrm{Ibid}$. 507: "Ni pueda ser el obispo presidente de audiencia secular, pues San Pedro lo vedó expresamente, como San Clemente lo cuenta. Y la razón está clara, pues cada oficio de éstos ha menester un hombre entero, y aún es poco. Harto mal vino a la dignidad episcopal, pues es tan poco estimada, que piense un obispo poder bien cumplir con ella con el tiempo que le sobra de otro oficio".

${ }^{47}$ En todos los textos de san Juan de Ávila destaca su enorme interés por destacar la gran carga de trabajo que debía tener el obispo, y su preocupación por que, en muchas diócesis, dada su extensión, era imposible una correcta administración. Ya desde el memorial de 1551 señaló que debían cambiarse los límites de las diócesis, como de hecho en parte hizo Felipe II. Cf. OC II, 508.
} 


\section{José RAMÓn Godino Alarcón}

Del deber de residencia, además, se podía sacar una complicación añadida, y era la relación con el clero regular. Desde hacía varios siglos habían surgido roces y conflictos entre el clero secular y regular por la función de cada uno en la asistencia espiritual de los fieles. Y una de las grandes preocupaciones de los obispos había sido intentar controlar a los religiosos de sus diócesis, en especial a los que regentaban parroquias. San Juan de Ávila, como buen presbítero secular, señaló que el obispo debía tener derecho de intervención sobre los religiosos en la medida en que lo permitiera el derecho. Esto era más fácil con un obispo presente que ausente ${ }^{48}$, y con ello se prevenían unos escándalos que debían ser frecuentes.

Del deber de residencia se desprendían otros deberes no menos importantes. En el breve tratado Lo que se debe avisar a los obispos, que en realidad es un sumario de reforma preparado para ser enviado a Pío IV ${ }^{49}$, el santo doctor señaló dos deberes del obispo de gran importancia para la reforma de la Iglesia: estar informado de los jóvenes con rasgos vocacionales y vigilar el ministerio de los confesores.

En los textos reformistas es muy común ver cómo el maestro señala constantemente que una de las causas de las dificultades de la Iglesia era la falta de información entre las distintas instancias de gobierno, la mayoría de las veces debido al escaso celo de quienes tenían la autoridad. Esto se veía especialmente, como hemos visto, en la selección de los candidatos a las sagradas órdenes. Mientras que lo más cómodo era esperar a que quien quisiera ser ordenado manifestase su deseo, Ávila señaló que el obispo debía adelantarse y buscar personas idóneas, y para ello debía tener una buena red de información, pues si no se iba a ver como "ave sin alas para volar" ${ }^{50}$. Tener esta red de vigilancia y de posterior formación era algo costoso, pero era necesario para poder comenzar a crear un clero fuerte y bien formado.

La esperanza de Juan de Ávila era el futuro clero, virtuoso y letrado. Pero, mientras tanto, se tenía que velar por el clero existente, muchas veces de formación deficiente. Esto los convertía en muchas ocasiones en un auténtico

\footnotetext{
${ }^{48} \mathrm{Ibid}$. 508: "Si algún religioso fuese cura en alguna iglesia parroquial, éste sea sujeto al obispo, pues este tal está en oficio de clérigo y no de monje. Porque cosa es muy fuera de razón que entienda uno en ovejas del prelado y no pueda ser corregido del mismo prelado (...)".

${ }^{49}$ Godino Alarcón, Los memoriales..., 463.

${ }^{50}$ OC II, 518: "El principal cuidado del obispo ha de ser cerca de las ánimas, y para esto ha menester clérigos buenos y sabios, pues sin ellos no puede más que ave sin alas para volar. Y por esto ha de tener mucho cuidado de saber los mancebos que hubiere virtuosos en su obispado; y ahora sea dándoles aparejo con que estudien en la ciudad donde el obispo está, o ahora sea enviándolos a estudiar a alguna universidad a costa de él; en todo caso, que cure de hacerlos letrados y favorecerlos todo lo posible. Y en tener muchos de éstos está su bienandanza para ser buen obispo. Y porque no los hay hechos, conviene que los haga de principio".
} 
peligro, sobre todo en el confesionario, por lo que el obispo debía estar atento especialmente a que la confesión no acarreara males y escándalos, que para nosotros en nuestros días serían impensables pero que en el siglo XVI no debían ser tan inusuales por lo que señaló el santo doctor ${ }^{51}$. Jugaba mucho en contra de la reforma la mala formación de los seglares, que eran llevados al engaño en muchos casos, y por ello el obispo debía hacer valer su autoridad para que los atropellos de los clérigos deficientes fueran denunciados y subsanados.

El problema de la formación del pueblo de Dios fue abordado con más amplitud en el memorial de $1561^{52}$. No entra tanto en las obligaciones del obispo como en las consecuencias de tener obispos preparados y virtuosos. Con obispos así era más fácil seleccionar al clero, y con un clero formado era muchos más sencillo disponer una instrucción necesaria para el pueblo, en especial enseñando el catecismo y las oraciones en español, o favoreciendo las escuelas de gramática y de latín.

El paso de los años, y el memorial de 1551, habían hecho que Ávila centrase sus esfuerzos en un clero adecuado, consciente de la grandeza del celibato y de la altura de su vocación. Pero tampoco le hizo olvidar que, en la imagen de los obispos, debía tenerse un especial cuidado por prevenir el lujo, en consonancia con el estilo de vida que él llevó. Por ello, en un breve párrafo del texto de 1561, el santo maestro no se olvidó de señalar la necesidad de una vida austera para los obispos, tan necesaria para la virtud como era que fueran doctos y letrados ${ }^{53}$. Ávila, lejos de ser un defensor del pauperismo, quiso advertir del peligro que podía traer para una diócesis la vanidad de un prelado.

De los memoriales a Trento, por lo tanto, podemos obtener datos muy interesantes para estudiar la figura del obispo, pero no podemos afirmar que el santo doctor hiciera una semblanza completa del perfil del obispo. Más bien

${ }^{51}$ Ibid. 516: "Muchos confesores dicen y hacen cosas malas con los penitentes, así aplicándose para sí las restituciones que se deben a personas ciertas, como induciendo a mal de deshonestidad a las mujeres, como en otras cosas semejantes. $\mathrm{Y}$ es tanta la ignorancia de los penitentes, que, aunque vean estos males de los confesores, no lo osan decir a quien lo remedie, creyendo que con el mismo vínculo es obligado al secreto el penitente como el confesor. Y de esta manera quédanse los tales confesores en sus oficios, con gran daño de muchos. Lo cual se remediaría si mandasen los obispos que se predicase al pueblo que, cuando con esos tales confesores encontrasen, lo hiciesen saber al obispo o a otra persona que le diese noticia de ello".

${ }^{52}$ Cf. Ibid. $578-587$.

${ }^{53}$ Ibid. 604: "El aparato de muchos prelados y de eclesiásticos con tapicerías, vajillas, vestidos de criados y cosas semejantes es tal que puede competir en vanidad con los caballeros y señores temporales, mandando lo contrario los concilios y enseñándolo los santos, y haciendo mucho daño al pueblo con su mal ejemplo, que es causa de ser imitado, con grave daño de los imitadores. A una ciudad vino un obispo, y quejábanse de él, diciendo que les había traído vestidos y trajes de la corte, y les había hecho mucho mal a su ciudad". 


\section{José Ramón Godino Alarcón}

apreciamos acentos y particularidades que debían ser cuidadas por obispos ya reformados, como venía sucediendo progresivamente en España, y como paulatinamente con las labores del concilio se fue extendiendo al resto de la Iglesia.

\section{Los consejos para la implementación de la reforma tridentina a través de los sínodos y del ejemplo de los obispos diocesanos}

El fin del concilio de Trento en 1563, marcó un antes y un después en la historia de la Iglesia. También para la concepción de la Iglesia y la reforma en san Juan de Ávila. Mientras que, hasta el fin del concilio, habían permanecido muchos puntos abiertos, incluso en clara discusión, en los que se podía opinar con cierta flexibilidad, el fin del concilio marcó unas líneas de actuación claras para conseguir la reforma de la Iglesia.

El maestro Ávila, en sus memoriales al concilio y en otros escritos, había sugerido bastantes puntos que no habían sido contemplados por el concilio ${ }^{54}$. Pero, una vez publicados todos los decretos de reforma, la tarea que esperaba a todos era ponerlos en práctica, y de una forma eficiente y lo más rápida posible. El santo doctor siguió escribiendo sobre la reforma, pero ya presentando, comentando e iluminando para llevar a la práctica lo mandado en Trento. En ningún momento encontramos contradicción alguna con el magisterio, sino la demostración de un auténtico manejo de los textos conciliares ${ }^{55}$.

El ministerio del obispo también se vio redimensionado tras la conclusión del concilio, pues este, finalmente le había otorgado una amplia autoridad para llevar a cabo la reforma. En su mano había quedado la fundación del seminario y la admisión de los candidatos al presbiterado, algo que Ávila había pedido insistentemente, aunque no había conseguido llegarse a aceptar el ambicioso plan de formación y exámenes que propusiera.

Sin duda alguna, la amplitud de los poderes del obispo fue la que facilitó que comenzara la reforma del clero. El papa debía velar por la elección de obispos dignos, que después vigilaran por la integridad moral y espiritual de los sacerdotes, y con más autoridad sobre los religiosos asentados en su diócesis. En Trento, el sacerdote había pasado de ser el responsable del culto a ser pastor de almas ${ }^{56}$.

\footnotetext{
${ }^{54}$ Un ejemplo muy conocido es el de la edad de ordenación, que para san Juan de Ávila no podía recibirse antes de los treinta años, y que finalmente el concilio estableció en veinticinco.

${ }^{55}$ Esto se aprecia también en la concepción del papel que debían tener las cabezas de la Iglesia. Por ejemplo, el papa pasó de ser considerado con una cierta prudencia (pidiendo que no entorpeciera la reforma) a ser el ejemplo de la Iglesia y a estar "en la cruz con Cristo" (cf. OC II. 566).

${ }^{56}$ Godino Alarcón, Los memoriales..., 467.
} 
Todo esto había sido comentado y promovido entre los prelados enviados por Felipe II y los teólogos y expertos consultados, se hubieran desplazado o no en al concilio. San Juan de Ávila, a través del arzobispo Guerrero, estuvo muy presente. En la carta $178^{57}$, fechada el 22 de diciembre de 1564, se aprecia cómo, incluso con el concilio todavía en marcha, se estaban dando pasos para poner en marcha la reforma. El punto de partida era el gran problema que ya se apreciaba en la carta conservada de 1547: "mas, ¿dónde los hallaremos" 58 .

El panorama en el arzobispado granadino no era precisamente esperanzador. A la zozobra de toda época de reformas se unía la inestabilidad social derivada de las peculiaridades sociales de la diócesis, de reciente cristianización y en la que pervivían numerosos moriscos y "cristianos nuevos", sobre todo en las Alpujarras ${ }^{59}$. San Juan de Ávila era consciente de que la predicación en las zonas moriscas era muy necesaria, y que el obispo debía velar por la pureza de la fe de los conversos. En otras diócesis más desarrolladas, como señala en el caso de Badajoz, ya se habían puesto en marcha equipos de predicadores, invirtiendo en ello todos los medios necesarios ${ }^{60}$. Por si fuera poco, un tema oscurecía aún más el panorama para el santo y el arzobispo: los brotes alumbrados que desestabilizaban el ambiente eclesiástico andaluz. A ello se refirió en un breve billete enviado en $1564^{61}$, del que podemos sacar la conclusión de que para Ávila el problema alumbrado seguía siendo muy cercano, y su única solución el dar un justo castigo a quienes cayeran en la herejía.

Sin embargo, el tema del que encontramos mayor referencia documental es el de la predicación en la diócesis. Ávila no se limitó a ser un consejero. En este caso, como en tantos otros, reveló un genio práctico considerable, ofreciendo nombres, medios y recursos para, por lo menos, empezar la tarea. Aunque no se aborde directamente, está claro que en el maestro latía la preocupación por la caridad pastoral del obispo, principalmente en el cuidado de los cristianos nuevos ${ }^{62}$.

\footnotetext{
${ }^{57}$ OC IV, 591-592. La datación de esta carta es de gran importancia, puesto que en origen se pensó que era de 1568, hasta que, después de los estudios de Sala Balust, se cotejó que por los mismos datos que ofrece san Juan de Ávila había que anticipar cuatro años la datación (san Juan de Ávila ponía el día y el mes en sus cartas, pero muy raramente señalaba el año).

${ }^{58}$ Cf. Ibid. 590.

${ }^{59}$ No olvidemos que la Guerra de las Alpujarras comenzó pocos años después, en 1568. En este conflicto serían martirizados algunos de los discípulos de san Juan de Ávila, empeñados por la zona en labores misioneras.

${ }^{60}$ OC IV, 591: "Y da a cada uno cuarenta mil maravedís y cuarenta fanegas de trigo; y aun, si yo le enviaba algunos, dijo que daría más (...)".

${ }^{61} \mathrm{Cf}$. OC IV, 778.

${ }^{62}$ Ibid. 592: "Y tengo este medio por muy provechoso para los cristianos nuevos, los cuales, viendo buen ejemplo, que no buscan sino ánimas, se suelen convertir más que con palabras; pues aquella caridad dejóla Cristo encendida por Él en los corazones de sus ministros, y es tan fuerte, que lo vence todo".
} 


\section{José RAMÓn Godino Alarcón}

Pero la situación eclesial urgía en temas capitales, y mientras el arzobispo Guerrero tomaba en cuenta la sugerencia del envío de predicadores y confesores, era necesario al mismo tiempo culminar con la obra reformista que tanto había costado promover en Trento. Pocos días después, el 19 de enero de 1565 , Juan de Ávila volvió a escribir una carta al prelado ${ }^{63}$. La situación española necesitaba una constante revisión en lo referente a las costumbres y la moralidad. El santo maestro señaló un tema en el que estaba especialmente preocupado y en el que debía intervenir el obispo: los falsos juramentos ${ }^{64}$. Este punto nos permite, por lo menos, subrayar una de las características que debían señalarse en el obispo reformado: la preocupación por las buenas costumbres y la necesidad, llegado el caso, de llamar la atención a los poderosos para que no solo teóricamente se buscara la perfección del pueblo ${ }^{65}$. Por ello Ávila propuso la eliminación de los juramentos, evitando así tomar el nombre de Dios en vano. De esta carta se desprende la gran confianza entre los dos personajes, y que, sin necesidad de ser consultado, san Juan de Ávila era capaz de escribir largas reflexiones para aconsejar a los prelados en temas que él consideraba de especial urgencia.

A los pocos meses de la misiva anterior, conservamos una nueva intervención del santo doctor del 10 de marzo de $1565^{66}$. La predicación en la diócesis de Granada se había puesto en marcha, y Ávila aconsejó escoger con especial cuidado a los predicadores, dándoles además objetos de piedad para poder llegar mejor a las gentes ${ }^{67}$. Todo esto suponía un comienzo, pero con facilidad podía quedarse en lo provisional. Por ello, era necesario que el arzobispo pusiese todo su cuidado en comenzar con la instrucción de los niños, uno de los temas más queridos para san Juan de Ávila y punto fundamental de su proyecto reformista ${ }^{68}$.

${ }^{63}$ Cf. Ibid. 596-598.

${ }^{64}$ Ibid. 597: "Y no nos maravillemos si Dios castigare a su pueblo por tantos juramentos quebrantados (...) Si deseamos no ser vencidos de turcos, no ser azotados de Dios con pestilencia y otras cosas (...). Que si con las obras irritamos a la ira de Dios, no la podrá impedir la oración ni la lengua".

${ }^{65}$ Ibid. 592: "Y si Dios diese a vuestra señoría valor para lo escribir al rey, poniéndola la cosa clara delante y el mucho peligro de su conciencia si no lo remedia, yo quedaré consolado". Sabemos que Felipe II llegó a conocer todos estos particulares y los estudió detenidamente por los manuscritos conservados en El Escorial, lo mismo que también sabemos que, aunque el rey valoró los consejos del santo doctor, por lo menos en el caso de los juramentos no siguió el consejo de nuestro autor.

${ }^{66}$ Cf. Ibid. 593-595. La datación de esta carta y las siguientes no es demasiado complicada, pues fueron guardadas como colección por un sobrino del arzobispo Guerrero. Por el tono de la carta, además, se parecía fácilmente la conexión entre la Carta 179 y la 178, pues abordan el tema del envío de predicadores por la diócesis.

${ }^{67} \mathrm{Ibid}$. 593: "Y los pueblos han menester todas estas salsas para comer su manjar".

${ }^{68}$ Ibid. 593: “(...) Traigo a la memoria a vuestra señoría lo que toca a la buena institución de la edad pueril, que tan perdida está. Conviene que, pues los que andan alescuela y otros, tienen edad para oír misa, la oigan domingos y fiestas (...)". El texto de la carta continúa intentando dar solución a un tema 
Aprovechando el caso de los niños y su atención religiosa, el maestro abordó un tema que exigía especial cuidado del obispo, como era la formación de los confesores. Este fue también un tema recurrente de Ávila, pero está en absoluta consonancia con la dinámica tridentina de recuperación de la vida sacramental. Como se puede apreciar, la caridad pastoral vuelve a ser el tema de fondo de esta carta, en la que se mira especialmente por el bien de los niños, futuro de la Iglesia, y la manera de llegar a ellos cuidando el trabajo de maestros y confesores.

Granada se enfrentaba, como podemos ver, a numerosos problemas que podían atajarse con la aplicación de los mandatos conciliares y la continuación de las prácticas reformistas. Pero no era el único caso en el que la reforma se quería poner en práctica en medio de especiales circunstancias. La sede primada de Toledo se hallaba vacía en ese momento tras el procesamiento de su arzobispo, Bartolomé de Carranza, quien a su vez era cercano a los círculos "avilistas". El resultado de esta coyuntura era que el sínodo provincial de Toledo debía ser presidido por el obispo de Córdoba, que al mismo tiempo era el "obispo" de san Juan de Ávila: Cristóbal de Rojas ${ }^{69}$. Ante semejante encomienda el obispo pidió su ayuda al maestro, quien elaboró para el concilio numerosos materiales: el discurso inaugural y dos textos sobre la aplicación del concilio, todos ellos plagados de referencias canónicas y comentarios de los textos emanados del tridentino.

De esta colaboración conservamos también algún rastro epistolar, que nos ilumina en la concepción del santo doctor sobre el episcopado. La Carta $182^{70}$ nos muestra el cariz de esta relación. Cristóbal de Rojas había recibido un encargo inesperado ${ }^{71}$ y necesitaba estar a la altura del encargo recibido, en el que iban a estar puestos los ojos de toda España. Para Ávila la situación era providencial, era el momento en el cual se podía exponer el trabajo realizado por los avilistas durante las décadas pasadas ${ }^{72}$. Era una ocasión que no se debía

que, ayer y hoy, sigue siendo preocupante: la falta de interés de los padres por la educación cristiana de sus hijos. Evidentemente, los tiempos han cambiado, pero es ejemplar ver cómo san Juan de Ávila no se conformó con ver las situaciones, sino que intento buscar salidas para garantizar la instrucción religiosa de los niños, y de paso también la de sus padres.

${ }^{69}$ Cf. OC I. 260-264.

${ }^{70}$ Cf. OC IV. 601-604.

${ }^{71} \mathrm{Ibid}$. 601: “(...) Me atrevo a suplicar a vuestra señoría me diga qué es el fin y pretensión de Jesucristo nuestro Señor en hacer a vuestra señoría presidente de este concilio, por un rodeo no pensado".

${ }^{72}$ Ibid. 601: “(...) Parece que podemos tener alguna conjetura de que vuestra señoría ha administrado bien la presidencia o superintendencia sobre su clero y ovejas, pues Dios le da superintendencia sobre pastores de muchas ovejas, porque estoy persuadido de la misericordia de nuestro Señor, que si vuestra señoría ejecuta este mandato del Señor como debe, que he de ser causa de gran reformación en los obispos y obispados del reino, pues éstos a quien Dios envía a vuestra señoría son los principales de él, y lo que en este concilio se hiciere será para todo él una gran luz y un ejemplo a quien sigan”. 


\section{José RAMÓn Godino ALARCón}

dejar pasar para el avance de la reforma, y en ello se puede apreciar otro de los conceptos fundamentales de Ávila: del mismo modo que el concilio había establecido que el clero, según la tradición de la Iglesia, debía su razón de ser del vínculo del obispo, los obispos no podían llevar nada a la práctica sin la necesaria colaboración de sus sacerdotes, por lo que tenían que poner especial cuidado en el trato, y en asegurarse la correcta formación en vista a la futura disponibilidad y eficiencia.

El obispo de Córdoba debía ser una persona buena, humilde y trabajadora. Sin embargo, el maestro le pidió que, junto a esas virtudes, desarrollara un auténtico liderazgo en el sínodo. Dios iba a hablar por su boca para llevar a cabo la reforma, de ahí que debía ser decidido.

¿Cuál debía ser el principal objetivo del sínodo? La reforma del clero y del laicado ${ }^{73}$. Para que esto pudiera suceder, el primer paso debía ser la virtud de los participantes. Unida a la virtud era necesaria la preparación intelectual, y la disposición para que el sínodo fuera ejemplar en su austeridad y piedad. Para ello era esencial el ejemplo de su presidente ${ }^{74}$.

La contribución de san Juan de Ávila al sínodo toledano fue ingente. Casi se puede decir que el maestro "dio el trabajo hecho" a la presidencia del sínodo, y que después esto pudo también ser aprovechado en Granada, donde también debía realizarse un sínodo provincial. Nos encontramos ante una colección de textos que es un auténtico vademécum de la aplicación del concilio de Trento a la realidad española, de ahí su vital importancia. El maestro fue consciente de lo que estaba en juego en estas convocatorias, puesto que contó para la redacción de estos textos con la ayuda de algunos colaboradores expertos, como fue el caso de Francisco Gómez en lo referente a la legislación canónica ${ }^{75}$.

Era necesaria una reforma estructural, que reordenara la vida eclesial. El remedio fundamental ya había sido señalado en los memoriales a Trento, el

${ }^{73}$ Ibid. 602: "Haga vuestra señoría cuenta que el Señor lo envía por celador y restituidor de su honra, que tan perdido está en la clerecía y el estado laical, y cíñase su espada de la palabra y verdad de Dios, y menéela con grande amor y fervor; y mate todo aquello que a la santa voluntad de Dios contradice".

${ }^{74}$ Ibid. 603: "No piense vuestra señoría persuadir a nadie de reformación, si él no va reformado".

${ }^{75}$ Gómez actuó como emisario e intermediario entre el anciano predicador y el sínodo toledano. La Carta 215 muestra la misión que tuvo que desempeñar, en un momento en el que el resultado del sínodo podía resultar incierto y haber sido cerrado en falso: "Ahora he oído decir que ese santo concilio se acaba presto, y he temido no sea causa de ello el poco gusto que se toma de entender en los negocios de Dios y el mucho de ir a descansar a sus casas; porque, estando las cosas tan fuera de sus quicios como por nuestros pecados están y habiendo tan mucho tiempo que en remedio de ellas no se ha entendido, no sé cómo en tiempo tan breve se pueden hacer muchas cosas y dificultuosas. Deseo que vuestra señoría hiciese cuenta que ése será el postrero concilio en que se vea, y que tuviese una santa soberbia de dar muy buena cuenta de esa ocasión que le dio nuestro Señor de poder hacerle muchos servicios un poco antes que de esta vida le lleve (...)" (OC IV, 685). 
control de quienes aspiraban al orden sacerdotal ${ }^{76}$. Unido a ello, mientras se regeneraba el estado clerical, los obispos debían tomar medidas prácticas, no actuar como ejecutores del poder real o permanecer en la indolencia. El concilio había dado un marco legal, pero cada obispo debía hacerlo realidad en su diócesis para que la reforma fuera efectiva, y eso implicaba también poner a su disposición cuantos medios económicos fueran necesarios ${ }^{77}$.

La preocupación educativa es otro de los aspectos que se sugiere a los obispos. Ya no solo con los candidatos a las sagradas órdenes, sino en bien de las almas, especialmente las de los niños, que necesitaban de una buena instrucción cristiana. Precisamente, uno de los puntos en los que fue más decidido el santo doctor fue en que los obispos tuvieran mayor libertad para que pudieran publicar catecismos y libros de oraciones en lengua vernácula, y se diera impulso al culto eucarístico, que en sí mismo ya era una catequesis.

Para un anciano como Juan de Ávila, que ya había luchado denodadamente por el éxito de Trento, sus anotaciones y textos para los sínodos provinciales son un reflejo de la tensión y el amor por la reforma que vivía, y de su deseo por contagiárselo a los obispos. Pesaba también enormemente la amenaza protestante, en la que España también podía caer si no tomaba en serio la necesidad de la reforma. Por ello era decisiva, junto a la intervención eclesiástica, la actuación decidida de la corona para garantizar el éxito y la implantación de la reforma.

Las Advertencias al concilio de Toledo ${ }^{78}$ ofrecen, en vista de esta situación, un completo programa para la actividad de los obispos. Por su amplitud solo podemos señalarlo, pero constituyó una auténtica guía para el ministerio episcopal:

- Una casa y un estilo de vida marcados por la modestia y la humildad.

- Rodearse de familia y servicios virtuosos, evitando toda apariencia de corte secular.

- Tener lección en la mesa, y disposición para acoger a pobres.

- Reformar el estado de los beneficiados de las catedrales a imagen de la casa del obispo.

- No enriquecerse con las rentas eclesiásticas.

- Residencia del obispo en la diócesis.

- Deber de predicación y de preparación teológica.

- Velar por la buena y abundante predicación en las catedrales.

\footnotetext{
${ }^{76}$ Cf. OC II. $488-489$.

${ }^{77} \mathrm{Cf}$. Ibid. 497-503. Aunque son palabras dirigidas a Trento, constituyen un ejemplo de la iniciativa que tenían que desempeñar los obispos para garantizar la reforma, aun a costa de enemistarse con otros cuerpos constituidos de sus obispados.

${ }^{78}$ Cf. OC II, 645-710.
} 


\section{José RAMÓn Godino Alarcón}

- Necesidad de la visita pastoral por parte del mismo obispo.

- Atender al mandato de convocar regularmente sínodos.

- Cuidado preferencial de pobres y viudas.

San Juan de Ávila, desarrollando y explicando estos puntos, no demostró ninguna originalidad. Al contrario, quiso ceñirse todo lo posible a la letra del concilio para ponerlo en práctica de la forma más rápida posible. Por esa razón, muchos de los puntos recogidos no habían sido capitales en sus memoriales conciliares, pero en este texto tienen un gran desarrollo (como sucede con el deber de residencia o la visita pastoral).

El maestro, llegado a la ancianidad, quiso hacer un servicio a la Iglesia. $\mathrm{Y}$, desde este punto de vista, debemos interpretar los textos dedicados a los sínodos, especialmente en lo referente a la concepción del obispo. Porque lo que estaba en juego en 1565 era la adecuación de los ministerios eclesiásticos a una nueva realidad, la modernidad. La reforma no fue propuesta como un castigo, o como una respuesta tardía a los protestantes, sino como una oportunidad para que resplandeciera de nuevo la Iglesia. El obispo debía ser, en su diócesis, el motor de la reforma.

El papel del obispo reformado permitió ofrecer nuevas vías, que no siempre han sido valoradas históricamente, y que solo en nuestros días han sido reconocidas $^{79}$. Gracias a las medidas tomadas por el concilio, que Juan de Ávila señaló en los textos de los sínodos, la Iglesia pudo proponer nuevas medidas disciplinares y cristianizadoras, precisamente la mayor preocupación que Ávila tenía en cuanto al "después de Trento". Unida a este cambio en la enseñanza de la fe, estuvo la reforma de la administración eclesiástica, propiciada por un clero mucho más apto y formado que el del siglo anterior. Tampoco se puede negar el influjo que tuvieron estas medidas en el desarrollo de una nueva espiritualidad, mucho más individualista y que tuvo su mayor exponente en el empuje misionero en el Nuevo Mundo, y la creación de nuevas órdenes religiosas ${ }^{80}$. Era la concreción de un plan particular, el avilista, en un nuevo contexto social y religioso.

Estamos hablando, por lo tanto, de Juan de Ávila como actor decisivo de la reforma católica ${ }^{81}$. Quizás el santo doctor no sabía que sería reconocido en el

\footnotetext{
${ }^{79}$ Véase Henry Outram Evennett, The Spirit of Counter-Reformation. The Birkbeck Lectures in Ecclesiastical History Given in the University of Cambridge in May 1951 (Cambridge: Cambridge University Press, 1968).

${ }^{80}$ Wolfgang Reinhard, «Gegenreformation als Modernisierung? Prolegomena zu einer Theorie des konfessionnellen Zeitalters» Archiv für Reformationsgeschichte 67 (1977): 226-252.

${ }^{81}$ Este concepto, que parece reciente, sin embargo, se remonta a la poco conocida obra de Wilhelm Maurenbrecher, Geschichte der katholischer Reformation (Nordlingen: Verlag der C. H. Beck'schen Buchhandlung, 1880).
} 
futuro como uno de sus actores, pero, por los textos, sobre todo la Carta $215^{82}$, fechada en noviembre de 1565 , deducimos que supo que no podía dejarse el trabajo a medio acabar, y que debían ser los obispos quienes hicieran el esfuerzo de poner en práctica la reforma. El mismo texto de la carta nos muestra la preocupación que en ese tiempo tuvo el maestro:

Ahora he oído decir que ese santo concilio se acaba presto, y he temido no sea causa de ello el poco gusto que se toma de entender en los negocios de Dios, y el mucho de ir a descansar a sus casas; porque, estando las cosas tan fuera de sus quicios como por nuestros pecados están y habiendo tan mucho tiempo que en remedio de ellas no se ha entendido, no sé cómo en tiempo tan breve se pueden hacer muchas cosas y dificultuosas ${ }^{83}$.

Los obispos eran los primeros que debían creerse la importancia de la reforma, llevándola a sus vidas (es curioso que en las Advertencias recuerde con tanta insistencia la conveniencia de una vida austera por parte del obispo, y en esta carta eche en cara a Cristóbal de Rojas que se quisiera cerrar pronto el sínodo para que los prelados volvieran a la comodidad de sus casas) y aprovechando la ocasión para hacer un auténtico servicio a la Iglesia y a Dios, ante quien tarde o temprano tendrían que responder ${ }^{84}$.

Quizá la insistencia, y el consejo de Ávila y otros muchos, más o menos conocidos que él, respecto a la responsabilidad del obispo en la reforma, hizo que el éxito de la reforma en España fuese notablemente superior a otras zonas de Europa, desde los círculos de la curia romana a Francia, o singularmente en los territorios de habla alemana ${ }^{85}$. La Reforma protestante sorprendió a España en medio de un proceso renovador, pero este no estaba concluido ni avanzaba por igual en todas las regiones. Aunque con mayor ventaja, la Iglesia española tuvo que hacer frente a una corriente heterodoxa y hostil que necesitaba una respuesta rápida y contundente. Y sufrió ante las carencias que tenía para reaccionar, siendo testigo de un proceso de décadas, después del cual no pudo restaurarse la unidad de la Iglesia.

San Juan de Ávila fue uno de los pocos, en aquel momento, que supieron conjugar la necesidad de aportar novedades con el deber de preservar la tradición, manteniendo en gran medida el esquema de trabajo reformista que había

${ }^{82}$ OC IV. $685-686$.

${ }^{83}$ Ibid. 685.

${ }^{84}$ Ibid. 686: "Y como quien en breve se ha de ver delante su Señor, haga tales hazañas, que ninguna cosa le parezca grave, ninguna dificultosa, pues el amor hace lo dificultoso fácil (...)”.

${ }^{85}$ Desgraciadamente esto ha pasado por alto en la historiografía española, y han tenido que ser autores extranjeros, especialmente desde Jedin, los que han señalado todos estos aspectos. Debemos señalar, sin embargo, que se han hecho algunos intentos en España para poner en valor este legado. Cf. Manuel Fernández Álvarez (dir.), La Contrarreforma (Madrid: S. A. de Promoción y Ediciones, 1986). 


\section{José RAMÓn Godino Alarcón}

comenzado en época tardomedieval. Debía llevarse a cabo una reforma de la Iglesia que la devolviera a un estado venerable, no una supresión de sí misma y de su dimensión visible. De ahí que, tras haber colaborado activamente con los obispos para el desarrollo de la asamblea tridentina, se permitiera señalarles las líneas principales de trabajo en el futuro, corrigiendo incluso su pereza o poca iniciativa.

Los escritos de 1565 , por lo tanto, responden a una nueva etapa en el proceso reformista, en el que la edad no iba a dejar participar tan decisivamente al santo doctor. A partir de los sínodos provinciales, la Iglesia debía imponerse a sí misma el cumplimiento de los decretos de Trento, y convertirlos en el "ariete" de su lucha contra la herejía. Para esta etapa Ávila señaló una serie de vías, que aprovecharon lo mejor de la época anterior y que después se desarrollaron:

- Extensión al clero secular de la exigencia mostrada en la época anterior por el movimiento religioso observante, e impulso de las nuevas órdenes nacidas en el contexto reformista ${ }^{86}$.

- Concepción de la misión de la Iglesia en dos ámbitos igualmente necesario: misiones populares y dinamismo misionero en Ultramar.

- Reforma del método teológico, especialmente de la escolástica. En este sentido tuvieron un peso decisivo la teoría de las "tres vías" de Cisneros y la posterior Escuela de Salamanca. No se debe despreciar tampoco la influencia de Erasmo en el primer tercio del siglo XVI, algo que también influyó en el pensamiento avilista.

- Renovación de la formación sacerdotal. Sin duda alguna, el punto más querido del programa reformista de san Juan de Ávila, y que hizo necesaria la fundación de nuevos centros de enseñanza ${ }^{87}$.

- Reforma del gobierno eclesiástico. Desde el tamaño y número de diócesis a la administración y a la distribución de las rentas eclesiásticas.

Todo esto, que ya estaba presente en el pensamiento de san Juan de Ávila, debía ser el proyecto que los obispos debían desarrollar para hacer efectiva la reforma tridentina. Cuidando la renovación interior, pero al mismo tiempo devolviendo la iniciativa a la Iglesia y a sus pastores después del descalabro protestante. En este sentido, como también se ha señalado

\footnotetext{
${ }^{86}$ José García Oro, «Conventualismo y Observancia. La reforma de las órdenes religiosas en los siglos XV y XVI», en Historia de la Iglesia en España. La Iglesia en la España de los siglos XV y $X V I$, vol. III-1, editado por Ricardo García Villoslada (Madrid: Biblioteca de Autores Cristianos, 1980), 210-350.

${ }^{87}$ Un ejemplo, ligado estrechamente a Juan de Ávila, de este punto, es el de la diócesis de Jaén, en la que estaba la Universidad de Baeza. Cf. Francisco Juan Martínez Rojas, «La formación cultural del clero giennense en el período pretridentino y la labor renovadora de San Juan de Ávila y la Universidad de Baeza», XX Siglos 52 (2003): 65-73.
} 
por parte de los expertos, el mecanismo defensivo estuvo presente y fue necesario.

El obispo, en esta nueva situación, debía defender la fe con contundencia, aplicando todos los medios necesarios, especialmente rechazando toda posibilidad de presencia protestante en su diócesis. En ese ambiente es lógico que se desarrollara la "teología controversista", de la mano de autores como Exk, Emser o Cocleo, y que se buscara una mayor alianza con el poder secular para tener el mayor control posible, tanto en el fuero interno como en el externo.

San Juan de Ávila fue afectado por estos mecanismos, especialmente a través del Índice de Valdés. Pero en ningún momento dudó de la necesidad de tomar aquellas medidas, ni de que debía adecuarse a lo que se le pidiera. Fue el primer convencido de que la reforma no había de pararse, y así vemos que se lo manifestó a los obispos de los que se conserva relación epistolar.

Testimonio de esta convicción personal de nuestro autor es el último escrito reformista conservado, Causas y remedios de las herejias ${ }^{88}$. Lo que dijo en este texto del papa, buenamente se puede extender a cada obispo en su diócesis $^{89}$. Ante el peligro de inacción por parte de los pastores, estaba el peligro de sucumbir por falta de celo y la necesidad de despertar.

Causas y remedios de las herejías, un texto fechado en 1567, no fue propiamente un texto reformista en el estilo de los escritos comentados anteriormente. Podemos definirlo como un tratado que mezcla la apologética, la profecía y el deseo de santidad que Juan de Ávila tuvo para sí y para toda la Iglesia $^{90}$. El maestro, en la etapa final de su vida, vivió preocupado por la doble amenaza infiel y protestante, ante la que no se respondía con la suficiente vigorosidad por la falta de vida cristiana. No dudó en hacer responsables de esta fragilidad al papa, los obispos y los reyes, usando un lenguaje duro y tajante. Si el papa y el rey no cumplían sus tareas, alguien debía señalárselo con la debida autoridad.

\footnotetext{
${ }^{88}$ OC II, 521-578.

${ }^{89} \mathrm{Ibid}$. 565-566: "Y, entre todos los que esto deben sentir, es el primero y más principal el supremo pastor de la Iglesia. Pues lo es en el poder, razón es que, como principal atalaya de toda la Iglesia, dé más altas voces para despertar el pueblo cristiano, avisándoles del peligro que tienen presente y del que es razón temer que les puede venir. Ábranse sus entrañas, y sean comidas con el santo celo de la casa de Dios que le está encomendada, para sentir sus caídas y para ofrecerse, si menester fuere, a muerte de cruz, a semejanza de aquel Señor cuyo vicario es, y de San Pedro, su primer antecesor, y a todo lo que menester fuere para remedio y reformación de la Iglesia".

${ }^{90}$ Cf. Godino Alarcón, Los memoriales..., 156.
} 


\section{Conclusión. El episcopado, fundamental en el proceso de confesio- nalización}

Después de haber hecho este recorrido a través de los escritos y la doctrina de san Juan de Ávila, creo que es evidente que, aunque no lo hiciera de forma sistemática, trazó un perfil definido del obispo y de su ministerio en una Iglesia renovada. Es, además, importante señalar su contribución en el proceso de cambio que atravesó la Iglesia en el siglo XVI, y que desembocaría en la confesionalización católica ${ }^{91}$. En España, este proceso se vivió con especial intensidad.

El papel del obispo se volvió decisivo en el proceso de uniformidad social que dio comienzo, para católicos y protestantes, tras la Paz de Augsburgo (1555). San Juan de Ávila fue testigo de estos hechos, evolucionando desde un punto de vista más optimista a estar informado sobre la teología controversista, como atestigua la parte de su biblioteca conservada hoy en día en Córdoba. Posiblemente, en su cabeza no estuvo que, con el tiempo, estos postulados llevarían a una progresiva supeditación de la autoridad religiosa a la temporal, especialmente de los obispos, que fueron asimilándose a figuras importantes del aparato burocrático.

En san Juan de Ávila, como hemos visto, el papel del obispo es el de un auténtico pastor, celoso por sus fieles, especialmente por el cuidado del clero y de la piedad de los más sencillos. Lo que, avanzando el siglo, llegaría a ser considerado una disciplina social, en Ávila fue una adecuación de la autoridad eclesiástica al ministerio apostólico originario. Es en este espíritu en el que deben leerse e interpretarse sus escritos, una auténtica lectura de la época tridentina y de su aplicación práctica.

\section{Bibliografía}

Ávila, Juan de. Obras Completas (4 vols.). Madrid: Biblioteca de Autores Cristianos, 2000-2003.

Azcona, Tarsicio de. La elección y reforma del episcopado español en tiempo de los Reyes Católicos. Madrid: Instituto P. Enrique Flórez, 1960.

Evennett, Henry Outram. The Spirit of Counter-Reformation. The Birkbeck Lectures in Ecclesiastical History Given in the University of Cambridge in May 1951. Cambridge: Cambridge University Press, 1968.

\footnotetext{
${ }^{91}$ Wolfgang Reinhard, «Confessionalizzazione forzata? Prolegomeni ad una teoria dell'età confessionale», Annali ell'Istituto storico italo-germanico in Trento 8, (1982): 13-38.
} 
El MiNISTERIO DEL OBISPO EN El PROGRAMA REFORMISTA DE SAN JUAN DE Ávila

Fernández Álvarez, Manuel (dir.). La Contrarreforma. Madrid: S. A. de Promoción y Ediciones, 1986.

Fernández Conde, Javier. «Decadencia de la Iglesia española bajomedieval y proyectos de reforma», en Historia de la Iglesia en España. La Iglesia en la España de los siglos XV y XVI, vol. II-2, editado por Ricardo García Villoslada, 417-462. Madrid: Biblioteca de Autores Cristianos, 1980.

García Oro, Jose. «Conventualismo y Observancia. La reforma de las órdenes religiosas en los siglos XV y XVI», en Historia de la Iglesia en España. La Iglesia en la España de los siglos XV y XVI, vol. III-1, editado por Ricardo García Villoslada, 210-350. Madrid: Biblioteca de Autores Cristianos, 1980.

García Villoslada, Ricardo. «La Contrarreforma. Su nombre y su concepto histórico», en Saggi storici intorno al Papato, 189-242. Roma: Pontificia Universidad Gregoriana, 1959.

Godino Alarcón, José Ramón. Los memoriales de reforma de san Juan de Ávila: fuentes de inspiración y análisis histórico-teológico. Madrid: Universidad San Dámaso, 2018.

"La escuela sacerdotal "avilista" (en prensa). Córdoba: 2021.

Corral Cano, Juan Miguel. Las fuentes en el Tratado del sacerdocio de san Juan de Ávila, a la luz del conjunto de sus escritos de teología y espiritualidad sacerdotal. Madrid: Universidad San Dámaso, 2019.

Granada, Luis de. Vida del Venerable Padre Maestro Juan de Ávila

Martínez Rojas, Francisco Juan. «La formación cultural del clero giennense en el período pretridentino y la labor renovadora de San Juan de Ávila y la Universidad de Baeza». XX Siglos 52, (2003): 65-73.

Maurenbrecher, Wilhelm. Geschichte der katholischer Reformation. Nordlingen: Verlag der C. H. Beck'schen Buchhandlung, 1880.

Navarro Sorní, Miguel. «San Juan de Ávila y la reforma de la Iglesia», en San Juan de Ávila, Doctor de la Iglesia, editado por Nicolás Álvarez de las Asturias, 49-85. Madrid: Universidad San Dámaso, 2013.

Reinhard, Wolfgang. «Gegenreformation als Modernisierung? Prolegomena zu einer Theorie des konfessionnellen Zeitalters». Archiv für Reformationsgeschichte 67, (1977): 226-252.

Reinhard, Wolfgang. «Confessionalizzazione forzata? Prolegomeni ad una teoria dell'età confessionale». Annali ell'Istituto storico italo-germanico in Trento 8, (1982): 13-37.

Tellechea Idígoras, José Ignacio. Felipe II y el Papado. Madrid: Fundación, 2004-2006. 